\title{
ELABORAÇÃO DE BEBIDA FERMENTADA UTILIZANDO CALDA RESIDUAL DA DESIDRATAÇÃO OSMÓTICA DE ABACAXI (Ananas comosus $\mathbf{L}$.
}

\section{PREPARATION OF FERMENTED BEVERAGE USING RESIDUAL SYRUP OF OSMOTIC DEHIDRATION OF PINEAPLE (Ananas comosus L.)}

\author{
Lucas Athayde Oliveira ${ }^{1}$, Frederico dos Santos Lordelo ${ }^{2}$, José Torquato de Queiroz Tavares ${ }^{3}$, \\ Marcia Luciana Cazetta ${ }^{4 凶}$ \\ ${ }^{1,2}$ Universidade Federal do Recôncavo da Bahia (UFRB), Centro de Ciências Agrárias, Ambientais e \\ Biológicas, Campus de Cruz das Almas, BA \\ ${ }^{3,4}$ Universidade Federal do Recôncavo da Bahia, Centro de Ciências Exatas e Tecnológicas, Campus de Cruz \\ das Almas, BA malulz@yahoo.com.br $\left({ }^{\bowtie}\right.$ Autor correspondente)
}

\begin{abstract}
Resumo
A industrialização de frutas emprega tecnologias que visam diminuir as perdas durante o transporte e armazenamento das frutas, além de agregar valor ao produto e aumentar sua vida de prateleira. Dentre as tecnologias mais utilizadas está a desidratação osmótica e produção de fruta cristalizada. Como sub-produtos destes processos sobra uma calda que ainda contém um elevado conteúdo de açúcares, além de reter o aroma e sabor da fruta. Assim, o objetivo deste trabalho foi aproveitar a calda residual da desidratação osmótica do abacaxi para elaboração de uma bebida fermentada. Para isso, a calda foi diluída até cerca de $25^{\circ} \mathrm{C}{ }^{\circ}$ Brix e tratada com metabissulfito de potássio para evitar a contaminação por leveduras invasoras e outros microrganismos. Ao mosto foi inoculada a levedura Saccharomyces cerevisiae e a fermentação foi conduzida em fermentadores plásticos, com três repetições, durante 90 dias. Para avaliar a qualidade do produto, foram realizadas análises físico-químicas e sensoriais. A análise sensorial (teste de aceitação) foi realizada através de escala hedônica estruturada, com um grupo de 30 provadores não-treinados constituído de alunos e funcionários da Universidade Federal do Recôncavo da Bahia, de ambos os sexos. Os experimentos resultaram em um fermentado de cor clara, levemente amarelado, com teor alcoólico de $12,3{ }^{\circ} \mathrm{GL}$. O fermentado foi bem aceito de acordo com a análise sensorial.
\end{abstract}

Palavras-chave: Fermentação, sub-produto, abacaxi

\section{Introdução}

O Brasil caracteriza-se como um dos principais produtores mundiais de abacaxi (Ananas comosus L.) e a região Nordeste responde pela maior produção, com destaque para Paraíba, Bahia e Rio Grande do Norte, seguida pela região Sudeste, onde Minas Gerais é o principal produtor 
(MARIN et al., 2008; ETENE 2010; IBGE, 2012). Segundo dados do IBGE (2010), a área plantada de abacaxi cresceu acima de $13 \%$ entre 2009 e 2010, sendo produzidos 1.470 .391 frutos em 2010. Em 2011 e 2012 as safras apresentaram valores similares (IBGE, 2012).

No entanto, a taxa de desperdício ainda é elevada. Estima-se que, no Brasil, o desperdício de alimentos oscile entre $40 \%$ e $80 \%$, sendo a maior parte no transporte e manuseio dos produtos (DIAS, 2003). No caso do abacaxi, mais de $90 \%$ da produção é consumida in natura e as perdas giram em tornam de $10 \%$ a $15 \%$, especialmente decorrentes do descasque trabalhoso e da necessidade de equipamentos para consumo e armazenamento do líquido (DURIGAN, 2004). Além disso, o transporte da fruta entre grandes distâncias dentro do país, ou mesmo na exportação, exige métodos de conservação e transporte cada vez mais eficientes (THÉ, et al., 2009).

Em vista disso, o desenvolvimento de técnicas de preservação dos alimentos, mantendo o máximo dos componentes nutricionais e das propriedades organolépticas, é uma forma de viabilizar o aproveitamento racional. Neste contexto, a industrialização surge como alternativa para reduzir as perdas, tanto no pico da safra, quando as frutas alcançam menores preços pelo excesso de oferta como na entressafra, disponibilizando a fruta para o consumo (ANDRADE et al., 2003; SOUZA NETO et al., 2004).

A desidratação osmótica tem se apresentado como uma ferramenta tecnológica importante para o desenvolvimento de novos produtos derivados de frutas que, além de diminuir as perdas póscolheita, aumenta o valor agregado da fruta sem perda do valor nutricional (TORREGGIANI e BERTOLO, 2001). Segundo MAIA et al. (2002) para a desidratação osmótica utilizam-se, em geral, soluções concentradas de sacarose (xarope osmótico). Assim, após o processo sobra uma calda, que além de apresentar grande concentração de açúcares, ainda retém o aroma e o sabor da fruta. Nas grandes indústrias a calda é reciclada e reutilizada em novas cristalizações ou destinada para fabricação de doces, como balas e pirulitos. Em pequena escala, no entanto, esse resíduo pode ser aproveitado para formulação de outros produtos.

Teoricamente, qualquer fruto ou vegetal que contenha umidade, açúcar e nutrientes para as leveduras pode ser utilizado como matéria-prima para a produção de bebidas alcoólicas fermentadas (MARTINELLI FILHO, 1983). A fabricação de fermentados de frutas já está bem estabelecida e muitas frutas tropicais são utilizadas com sucesso nesse processo como a laranja (CORAZZA et al., 2001), camu-camu (MAEDA e ANDRADE, 2003), acerola (SANTOS et al., 2005), caju (TORRES NETO et al., 2006) e jaca (ASSIS NETO, 2010). Embora exista uma grande variedade de fermentados de frutas, somente os fermentados de uva podem receber a denominação de "vinho". Para outras frutas, a palavra vinho (ou fermentado) deve ser seguida obrigatoriamente pelo nome da fruta (CORAZZA et al., 2001; SANTOS et al., 2005). Bebidas fermentadas de frutas constituem 
produtos promissores devido à tendência de aceitação em pesquisas de consumo (SANDHU e JOSHI, 1995). Assim, o objetivo deste trabalho foi estudar a elaboração de uma bebida fermentada aproveitando a calda residual da desidratação osmótica de abacaxi como substrato.

\section{Material e métodos}

\section{Matéria-prima}

A matéria prima utilizada (calda) para a fermentação foi obtida após a desidratação osmótica de abacaxi (Ananas comosus L.), realizada no Laboratório de Tecnologia de Alimentos da Universidade Federal do Recôncavo da Bahia, e cedida para a realização deste trabalho.

\section{Preparo do pé-de-cuba}

Foram preparados 3 litros de pé-de-cuba utilizando-se sacarose com 24,5 ${ }^{\circ}$ Brix e suplementados com $\mathrm{KCl}$ 0,12 \%, $\mathrm{NH}_{3}\left(\mathrm{PO}_{4}\right)$ 0,5\% e $\mathrm{MgSO}_{4} .7 \mathrm{H}_{2} \mathrm{O}$ 0,07\% como meio de propago. O pé-de-cuba foi inoculado com leveduras liofilizadas (Saccharomyces cerevisiae) na proporção de 3,4 g.L. $\mathrm{L}^{-1}$. Para evitar contaminação foi adicionado metabissulfito de potássio a 0,2 g. $\mathrm{L}^{-1}$. A multiplicação da levedura (pé-de-cuba) foi feita sob aeração forçada por 2 dias. Em seguida foi feito um novo pé-de-cuba com a calda proveniente da desidratação osmótica de abacaxi, diluída até 25 ${ }^{\circ}$ Brix e com os mesmos sais descritos acima, para adaptação das leveduras ao meio de fermentação. Após dois dias, o pé-de-cuba foi adicionado ao mosto para iniciar a fermentação.

\section{Preparo do Mosto}

A calda bruta da desidratação osmótica do abacaxi apresentou ${ }^{\circ}$ Brix inicial de 82,2. Para a fermentação, esta foi diluída até uma concentração de $25,8{ }^{\circ}$ Brix, não sendo necessária a adição de sacarose. Em seguida, foi realizada a sulfitagem com metabissulfito de potássio a $0,05 \mathrm{~g} \mathrm{~L}^{-1}$ para evitar a contaminação por leveduras invasoras e outros microrganismos. Em seguida, foi adicionado o pé-de-cuba, na concentração de cerca de $70 \mathrm{~mL} . \mathrm{L}^{-1}$ de mosto.

\section{Fermentação}

A fermentação ocorreu em vasilhames plásticos de 6 litros devidamente lacrados, utilizandose 3/4 de sua capacidade. Na porção superior dos vasilhames foram acopladas mangueiras como suspiro, submersas em água, para liberação de $\mathrm{CO}_{2}$ e para evitar contaminação por entrada de ar. Além disso, foram acopladas torneiras para realização das trasfegas e retirada de amostras.

As fermentações foram iniciadas logo após a adição do pé-de-cuba ao mosto, a uma temperatura variando entre $27^{\circ} \mathrm{C}$ e $31^{\circ} \mathrm{C}$. A fermentação teve duração de 90 dias, sendo realizadas 
trasfegas aos 30 e 60 dias (a terceira trasfega foi dispensada devido ao bom grau de pureza do fermentado). O acompanhamento da fermentação e da qualidade do fermentado foi realizado através de análises físico-químicas. As fermentações e as análises foram realizadas em triplicata.

\section{Sólidos Solúveis Totais (SS)}

A determinação do teor de sólidos solúveis foi realizada por meio de refratômetro manual, com escala de 0 a $33^{\circ}$ Brix, conforme Normas Analíticas do Instituto Adolfo Lutz (1985), onde cada ${ }^{\circ}$ Brix representa aproximadamente $80 \mathrm{~g}$ a 90 g de açúcar dissolvido para cada litro de mosto e 10 a $20 \mathrm{~g}$ de outros compostos.

\section{Determinação do $\mathrm{pH}$}

A determinação do $\mathrm{pH}$ foi realizada por meio de leitura direta com potenciômetro digital, utilizando 10 mL da amostra, segundo Normas Analíticas do Instituto Adolfo Lutz (1985).

\section{Determinação de Açúcares Redutores e Não-Redutores}

A determinação dos açúcares redutores foi realizada utilizando-se o método de Lane-Eynon, conforme Normas Analíticas do Instituto Adolfo Lutz (1985) e Moretto et al. (1988). Para determinação dos açúcares totais, foi utilizado o mesmo método, porém o mosto foi previamente hidrolisado com adição de ácido clorídrico concentrado e levado ao banho-maria a $67^{\circ} \mathrm{C}$ a $70^{\circ} \mathrm{C}$ por 15 minutos; em seguida, o $\mathrm{pH}$ foi neutralizado com $\mathrm{NaOH}$. Os açúcares não redutores foram determinados pela diferença entre os açúcares totais e redutores.

\section{Determinação do Teor Alcoólico}

Para determinação do teor alcoólico, $200 \mathrm{~mL}$ do fermentado foram destilados, obtendo-se $180 \mathrm{~mL}$, que foi completado para $250 \mathrm{~mL}$ com água destilada e esfriado a $20^{\circ} \mathrm{C}$ em banho de gelo. Em seguida, o grau alcoólico foi determinado com alcoômetro de Gay-Lussac, segundo Normas Analíticas do Instituto Adolfo Lutz (1985) e Moretto et al. (1988).

\section{Determinação de Acidez Titulável (AT)}

A determinação da acidez titulável foi realizada por meio de titulação volumétrica com solução de $\mathrm{NaOH}$ 0,1 N e solução alcoólica de fenolftaleína 1 \% como indicador, conforme Normas Analíticas do Instituto Adolfo Lutz (1985) e Moretto et al. (1988).

\section{Determinação da Acidez Volátil}

A acidez volátil foi determinada volumetricamente por titulação, após a destilação da amostra, segundo Moretto et al. (1988). 


\section{Determinação da Acidez Fixa}

A acidez fixa foi determinada pela diferença entre a acidez total e a volátil conforme metodologia descrita por Moretto et al. (1988).

\section{Avaliação Sensorial}

A avaliação sensorial foi realizada mediante uma escala hedônica, estruturada de 1 a 9 pontos, correspondendo a nota 1 a "desgostei muitíssimo" e a nota 9 a "gostei muitíssimo". Foram realizados testes de preferência para estimar aroma, sabor, doçura, acidez, adstringência, amargor, aparência, cor, transparência, aceitação global do fermentado e intenção de compra. Amostras foram colocadas em copinhos plásticos, codificados com números de três algarismos e servidas ao grupo provador. O grupo de provadores não-treinados foi composto de 30 pessoas de ambos os sexos, constituídos de alunos e funcionários da Universidade Federal do Recôncavo da Bahia, com idades variando entre 20 e 40 anos.

\section{Resultados e discussão}

As fermentações foram iniciadas com uma concentração de $25,8^{\circ}$ Brix. Segundo SANTOS et al. (2005), o teor alcoólico do vinho depende diretamente do teor de açúcar do mosto, sendo que um mosto pobre em açúcar resulta em vinhos com baixa graduação alcoólica.

Após 30 dias de fermentação a concentração de sólidos solúveis caiu para cerca de $14{ }^{\circ}$ Brix, permanecendo neste valor até o final do processo. Esses valores podem ser explicados pela presença de substâncias não-fermentescíveis dissolvidas no mosto, pois os sólidos solúveis não são, necessariamente, constituídos de açúcares na sua totalidade (CORAZZA et al., 2001; SILVA et al., 2005). Isto também é observado em fermentados de frutas, os quais também costumam apresentar ${ }^{\circ}$ Brix final entre $7{ }^{\circ}$ Brix e $12{ }^{\circ}$ Brix para diferentes fermentados de frutas (CORAZZA et al.,2001; DIAS et al., 2003; ASSIS NETO et al., 2010).

As concentrações de açúcares redutores e açúcares totais permaneceram em torno de 8,0\% a partir de 30 dias. Esses valores indicam que praticamente todo o açúcar foi consumido nos primeiros dias da fermentação. Os índices de acidez volátil, que indicam a concentração de ácido acético e seus derivados, atingiram, em média, 4,03 meq. $\mathrm{L}^{-1}$ após noventa dias de fermentação. Esses valores estão dentro dos padrões exigidos pela legislação brasileira, segundo a qual devem ser menores do que $20 \mathrm{meq} / \mathrm{L}$ (Brasil, 1997). Esse teor de acidez é semelhante ao descrito em fermentados de frutas, como o fermentado de acerola produzido por SANTOS et al. (2005), de 4,36 meq. $\mathrm{L}^{-1}$. 
A acidez total do fermentado de calda de abacaxi foi de 45,10 meq. $\mathrm{L}^{-1}$. Esses valores estão próximos da faixa exigida pela legislação Brasileira para acidez total em fermentados de frutas (Brasil, 1997). A acidez fixa do fermentado apresentou valores médios de 41,07 meq.L ${ }^{-1}$. Os valores de acidez fixa e total foram bem menores do que aqueles descritos por CHIARELLI et al. (2005) para fermentados de jabuticaba, polpa e casca, de 208,98 meq.L $\mathrm{L}^{-1}$ e 227,75 meq. $\mathrm{L}^{-1}$, respectivamente.

$\mathrm{O}$ pH apresentou queda ao longo do processo, sendo de pH 4,0 no início da fermentação e de 3,09 após 90 dias (Tabela 1). A acidez e o pH dos vinhos são decorrentes da produção de ácidos orgânicos, como ácido succínico, acético, lático, entre outros. O baixo pH dos fermentados é um fator importante para inibir a contaminação bacteriana do vinho (CHIARELLI et al., 2005; TORRES NETO et al., 2006), além de favorecer o crescimento das leveduras (MUNIZ et al., 2002), que são microrganismos que apresentam crescimento ótimo em pHs ácidos.

Esses valores de $\mathrm{pH}$ foram similares aos de fermentados de diferentes frutas. CORAZZA et al. (2001) obtiveram um pH final de 3,3 em fermentado de laranja. Em fermentados de jabuticaba (polpa e casca) foram atingidos pHs finais de 3,3 e 7,8, respectivamente (ASQUIERI et al., 2004). LOPES \& SILVA (2006) obtiveram para o fermentado de figo da índia um pH final de 3,5.

O grau alcoólico final do fermentado foi de $12,3{ }^{\circ} \mathrm{GL}$ (Tabela 1). Estes teores estão dentro dos padrões recomendados pela Legislação Brasileira, segundo a qual fermentados de frutas devem apresentar graduação alcoólica entre $10^{\circ} \mathrm{GL}$ e $14^{\circ} \mathrm{GL}$ (CORAZZA et al., 2001). Segundo SANTOS et al. (2005), vinhos com menos de $9^{\circ} \mathrm{GL}$ não são estáveis e avinagram com facilidade.

\begin{tabular}{|c|c|c|}
\hline Análises Físico-Químicas & $\begin{array}{l}\text { Valores } \\
\text { obtidos }\end{array}$ & $\begin{array}{l}\text { Desvio } \\
\text { padrão }\end{array}$ \\
\hline${ }^{\circ}$ Brix & 14,00 & 0,00 \\
\hline $\mathrm{pH}$ final & 3,1 & $\pm 0,01$ \\
\hline Acidez total (meq.L ${ }^{-1}$ de ácido acético) & 45,10 & $\pm 0,16$ \\
\hline Acidez volátil (meq.L L $^{-1}$ de ácido acético) & 4,03 & $\pm 0,27$ \\
\hline Acidez fixa (meq.L Le $^{-1}$ de áido acético) & 41,07 & $\pm 0,24$ \\
\hline Teor alcoólico $\left({ }^{\circ} \mathrm{GL}\right)$ & 12,3 & $\pm 0,29$ \\
\hline Açúcares redutores $(\%)$ & 7,96 & $\pm 0,20$ \\
\hline Açúcares não-redutores (\%) & 0,23 & $\pm 0,13$ \\
\hline Açúcares totais $(\%)$ & 8,25 & $\pm 0,19$ \\
\hline
\end{tabular}

Os teores alcoólicos do fermentado de calda de abacaxi foram similares aos de fermentados de frutas, como os de laranja, que apresentaram teor alcoólico em torno de $10^{\circ} \mathrm{GL}$ (CORAZZA et al., 2001; GURAK e BORTOLINI, 2010) e de jabuticaba, $12^{\circ} \mathrm{GL}$, obtido por CHIARELLI et al. (2005). Isso mostra que a calda de abacaxi apresentou um comportamento semelhante ao dos fermentados de frutas, mostrando-se bastante apropriada para a fabricação de bebidas fermentadas, 
com a vantagem de não ter sido necessário acrescentar sacarose ao mosto para corrigir o ${ }^{\circ}$ Brix, uma prática muito comum na produção de fermentados de frutas.

Como produto acabado, o fermentado de calda da desidratação osmótica de abacaxi apresentou aparência límpida, cor muito clara, levemente amarelada, e sabor adocicado.

\section{Análise sensorial}

De acordo com a escala hedônica, cuja escala varia de 1 a 9 pontos, os atributos relacionados ao aroma, sabor e aparência ficaram com valores médios entre 6,4 e 7,0 para o fermentado de calda de abacaxi, correspondendo a "gostei ligeiramente" e "gostei regularmente" na escala hedônica (Tabela 2 e Figura 1).

Tabela 2 - Notas atribuídas ao produto final de acordo com escala hedônica. Atributos Avaliados

\begin{tabular}{|c|c|c|c|c|c|c|c|}
\hline Aroma & & & Sabor & & & Aparência & $\begin{array}{c}\text { Aceitação } \\
\text { Global }\end{array}$ \\
\hline \multirow{2}{*}{6,4} & Doçura & Acidez & Adstringência & Amargor & Cor & Transparência & \multirow{2}{*}{7,0} \\
\hline & 5,8 & 6,4 & 6,8 & 6,8 & 6,8 & 7,0 & \\
\hline
\end{tabular}

Com relação aos atributos aparência (cor e transparência) o fermentado de calda de abacaxi apresentou valores médios em torno de 7,0, correspondendo, na escala hedônica, a "gostei regularmente". Segundo MEILGRAARD et al. (1991) a aparência é frequentemente o único atributo em que se baseia a decisão de rejeitar ou não o alimento. Assim, pode-se concluir que o produto possui potencial de aceitação pelo consumidor. A aceitação global do fermentado de calda de abacaxi ficou com média 7,0 na escala hedônica (Figura 1).

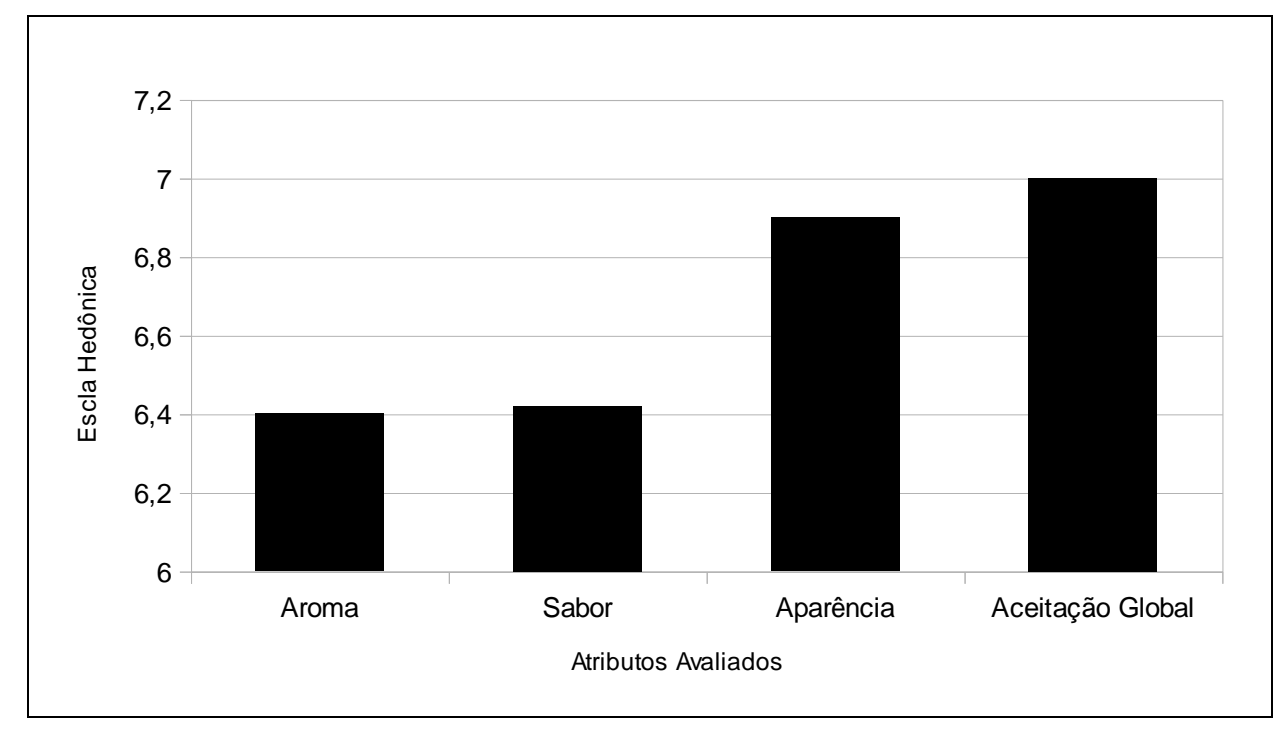

Figura 1- Análise sensorial do fermentado de calda da desidratação osmótica de abacaxi. 
De acordo com os comentários de alguns provadores, o fermentado necessitou apresentar mais aroma e sabor de abacaxi. De fato, embora a calda ainda preservasse o aroma e sabor da fruta, estes não permaneceram no produto fermentado final. Os resultados da pesquisa de intenção de compra do produto final foram coerentes com os resultados da análise sensorial, sendo que $50 \%$ dos provadores responderam que "provavelmente comprariam" o produto (Figura 2).

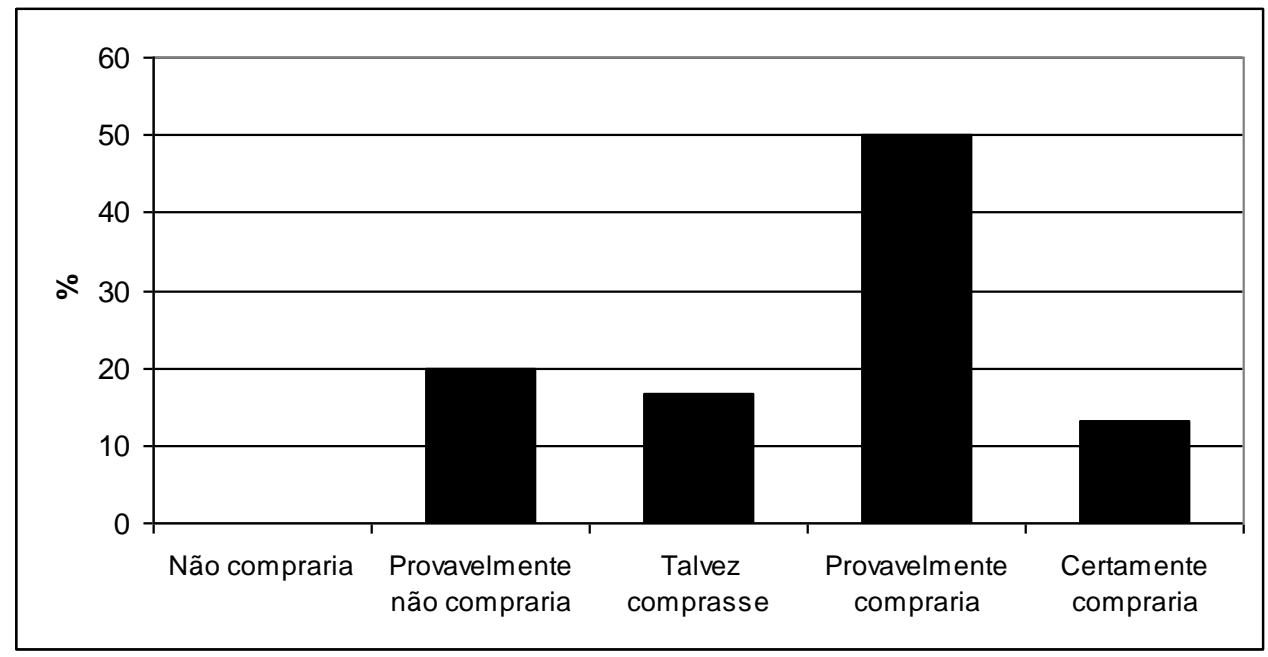

Figura 2- Gráfico de intenção de compra do fermentado de calda da desidratação osmótica de abacaxi.

\title{
4 Conclusões
}

A calda residual da desidratação osmótica de abacaxi mostrou-se um bom substrato para fermentação alcoólica, constituindo um subproduto promissor para a fabricação de bebidas fermentadas. A calda resultou em uma bebida de aparência, aroma e sabor agradáveis. No entanto, há necessidade de aperfeiçoar a técnica para o desenvolvimento de uma bebida com sabor e aroma de fruta mais acentuados e, consequentemente, com maior apelo comercial.

\begin{abstract}
The industrialization of fruit employs technologies to reduce losses during transportation and storage of fruits, besides adding value to the product and increase its shelf life. Among the key technologies used is dehydration and the production of candied fruit. As a by-product of these processes still remains a syrup that contains a high sugar content, and retain the flavor of the fruit. Thus, this study aimed to harness the residual syrup osmotic dehydration of pineapple (Ananas comosus L.) for preparation of a fermented beverage. For this, the solution was diluted to about 25 ${ }^{\circ}$ Brix and treated with potassium metabisulfite to prevent contamination by invasive yeast and other microorganisms. The must was inoculated with yeast Saccharomyces cerevisiae and fermentation was conducted in plastic fermenters, in three replicates, during 90 days. To assess the quality of the product were analyzed with physicochemical and sensory properties. The sensorial analysis (acceptance test) was performed using hedonic scale, with a group of 30 judges composed of untrained students and staff of the Universidade Federal do Recôncavo da Bahia of both sexes.
\end{abstract}


The experiments resulted in a fermented pale, slightly yellowish, with an alcohol content of $12.3^{\circ}$ $G L$. The fermentation was well accepted according to sensory analysis.

Key-words: fermentation, by-product, pineaple

\section{Referências}

ASSIS NETO, E. F.; CRUZ, J. M. P.; BRAGA, A. C. C.; SOUZA, J. H. P. Elaboração de bebida alcoólica fermentada de jaca (Artocarpus heterophyllus Lam.). Revista Brasileira de Tecnologia Industrial, v. 4, n. 2, p. 186-197, 2010.

ANDRADE, S. A. C.; METRI, J. C.; BARROS NETO, B.; GUERRA, N. B. Desidratação osmótica do jenipapo (Genipa americana L.). Ciência e Tecnologia de Alimentos. v. 23, n. 2, p. 276-281, 2003. http://dx.doi.org/10.1590/S0101-20612003000200029

AQUARONE, E., BORZANI, W., SCHIMIDELL, W., LIMA, U. A., HASHIZUME, T. Biotecnologia Industrial: Biotecnologia na Produção de Alimentos. São Paulo: Edgard Blücher, 523p., 2001.

ASQUIERI, E. R.; CANDIDO, M. A.; DAMIANI, C.; ASSIS, E. M. Fabricacíon de vino blanco y tinto de jabuticaba (Myrciaria jaboticaba Berg) utilizando la pulpa y la cáscara respectivamente. Alimentaria. v. 355, n. 1, p. 97-109, 2004.

BRASIL, Decreto n ${ }^{\circ} 2314$. Dispõe sobre a padronização, a classificação, o registro, a inspeção, a produção e a fiscalização de bebidas. Diário Oficial da República Federativa do Brasil, 1997.

CORAZZA, M. L.; RODRIGUEZ, D. G.; NOZAKI, J. Preparação e caracterização de vinho de laranja. Química Nova. v. 24, n.4, p. 449-452, 2001.

CHIARELLI, R. H. C.; NOGUEIRA, A. M. P.; VENTURINI FILHO, W. G. Fermentados de jabuticaba (Myrciaria cauliflora Berg): processos de produção, características físico-químicas e rendimento. Brazilian Journal of Food Technology. v. 48, n. 4, p. 277-282, 2005.

DIAS, M. C. Comida jogada fora. Correio Braziliense, 31 de Agosto de 2003. Disponível em :<http://www.consciencia.net/2003/09/06/comida.html.> Acesso em maio de 2005.

DELANOE, D.; MAILLARD, C.; MAISONDIEU, D. O. O vinho: da análise à elaboração. Portugal: EUROAGRO Europa-América Ltda., 230p, 1989.

DURIGAN, J. F. Processamento mínimo de frutas e hortaliças. Anais da $11^{\text {a }}$ Semana Internacional da Fruticultura, Floricultura e Agroindústria, 13 a 16 de setembro, Centro de Convenções de Fortaleza (CE), 2004.

ETENE - Escritório Técnico de Estudos Econômicos do Nordeste. 2010. Produção e área colhida de abacaxi no Nordeste. Informe Rural ETENE. Ano 4, n. 19.

GURAK, P. D.; BORTOLINI, F. Produção e aceitabilidade de fermentado de laranja no Alto Uruguai catarinense. Revista Brasileira de Tecnologia Agroindustrial. v. 4, n. 2, p. 132-140, 2010.

IBGE - Instituto Brasileiro de Geografia e Estatística. Disponível em: www.sidra.ibge.gov.br. Acesso em fevereiro de 2011.

INSTITUTO ADOLFO LUTZ. Normas analíticas do Instituto Adolfo Lutz: métodos químicos e físico-químicos para análise de alimentos. 3 ed. São Paulo-SP, vol. 1, p. 533, 1985.

LOPES, R. V. V.; SILVA, F. L. H. Elaboração de fermentados a partir de figo-da-Índia. Revista de Biologia e Ciência da Terra. v. 6, n. 2, p. 305-315, 2006.

MAEDA, R. N.; ANDRADE, J. S. Aproveitamento do camu-camu (Myrciaria dúbia) para produção de bebida alcoólica fermentada. Acta Amazônica. v. 33, n. 3, p. 489-497, 2003. http://dx.doi.org/10.1590/S004459672003000300014 
MAIA, G. A., FIGUEIREDO, R. W., SANTOS, P. H. M. Técnica aumenta tempo de conservação da goiaba. Revista de Ciência e Tecnologia. v. 1, n.4, p. 11 - 12, 2002.

MARIN, J. O. B.; CARVALHO, S. P.; PRADO, L. A.; PEREIRA, J;M. Panorama geral da produção de abacaxi no Brasil e comportamento sazonal dos preços do abacaxi "pérola" comercializados em Goiás. SOBER: XLVI Congresso da Sociedade Brasileira de Economia, Administração e Sociologia Rural. Realizado no período de 20 a 23 de julho de 2008.

MARTINELLI FILHO, A. Tecnologia de vinhos e vinagres de frutas. Piracicaba: Departamento de Tecnologia Rural da ESALQ/USP. 130 p, 1983.

MEILGAARD, M; CIVILlE, G. V; CARR, B. T. Sensory evaluation Techniques. Boca Raton: CRC PRESS, 394p, 1991.

MORETTO, E.; ALVES, R. F.; CAMPOS, C. M. T.; ARCHER, R. M. B.; PRUDÊNCIO, A. J. Vinhos e vinagres: processamento e análises. Florianópolis: UESC, 167p., 1988.

MUNIZ, C. R.; BORGES, M. F.; ABREU, F. A. P.; NASSU, R. T.; FREITAS, C. A. S. Bebida fermentada a partir de frutos tropicais. Boletim do CEPPA, v. 20, n. 2, p. 309-322, 2002.

REGULY, J. C. Biotecnologia dos processos fermentativos. Pelotas: Editora UFP, 222p., 1998.

SANDHU, D. K.; JOSHI, V. K. Technology, quality and scope of fruit wines especially apple beverages. Indian Food Industry. v. 14, n. 1, p. $24-34,1995$.

SANTOS, S. C.; ALMEIDA, S. S.; TOLEDO, A. L.; SANTANA, J. C. C.; SOUZA, R. R. Elaboração e análise sensorial do fermentado de acerola. Brazilian Journal of Food Technology. $5^{\text {a }}$ SIPAL, p. 47-50, março, 2005.

SOUZA NETO, M. A.; MAIA, G. A.; LIMA, J. R.; FIGUEIREDO, R. W.; SOUZA FILHO, M. S. M.; LIMA, A. S. Cinética da desidratação osmótica de manga. Publicatio UEPG Ciências Exatas e da Terra, Ciências Agrárias e Engenharia. v. 10, n. 2, p. 37-44, 2004.

THÉ, P. M. P.; NUNES, R. P.; CARVALHO, V. D. Efeitos de tratamentos pós-colheita sobre os fatores que influenciam na textura de abacaxis cv Smooth Cayenne. Revista Ceres, v. 56, n. 6, p. 705-712, 2009.

TORREGGIANI, D.; BERTOLO, G. Osmotic pre-treatments in fruits processing: chemical, physical and structural effects. Journal of Food Engineering. v. 49, n. 4, p. 247-255, 2001. http://dx.doi.org/10.1016/S0260-8774(00)00210-7

TORRES NETO, A. B.; SILVA, M. E.; SOLVA, W. B.; SWARNAKAR, R.; HONORATO, F. L. Cinética e caracterização físico-química do fermentado do pseudofruto do caju (Anacardium occidentale L.). Quimica Nova. v. 29, n. 3, p. 489-492, 2006. http://dx.doi.org/10.1590/S0100-40422006000300015

Submetido em 18 mar. 2011, Aceito para publicação em 21 mai. 2012. 